\title{
PATENT SIDE BRANCHES DO NOT AFFECT CORONARY BLOOD FLOW IN INTERNAL THORACIC ARTERY-LEFT ANTERIOR DESCENDING ANASTOMOSIS: AN EXPERIMENTAL STUDY
}

Claudio Pragliola, $\mathrm{MD}^{\mathrm{a}}$

Mario Gaudino, MD ${ }^{\mathrm{a}}$

Gabriele Bombardieri, MDa

Cynthia Barilaro, $\mathrm{MD}^{\mathrm{b}}$

Piergiorgio Bruno, $\mathrm{MD}^{\mathrm{a}}$

Carmelita Varano, $\mathrm{MD}^{\mathrm{b}}$

Tiberio Santoro, $\mathrm{MD}^{\mathrm{a}}$

Gianfederico Possati, MD
Background: It has been reported that large side branches of internal thoracic artery grafts may steal flow from the coronary circulation. Material and methods: To assess the importance of the side branches, we measured the proximal and distal flow and pressures (mean subclavian artery pressure and mean arterial anastomotic pressure) at baseline and during infusion of adenosine $(0.5 \mathrm{mg} / \mathrm{kg} / \mathrm{min})$ in 10 Landrace pigs in which an internal thoracic artery-left anterior descending anastomosis was constructed without interruption of the side branches. The difference between proximal and distal flow was considered to represent the blood flow of the internal thoracic artery side branches. Measurements were then repeated after surgical occlusion of all the side branches. Results: At baseline, blood flow of the side branches represented $18 \%$ of the total flow in the proximal internal thoracic artery, and this percentage remained constant under the infusion of adenosine, which caused a $220 \%$ increase of the cardiac index and a $368 \%$ increase of the proximal flow. The infusion reduced the gradient along the left internal thoracic artery (mean subclavian artery pressure-mean arterial anastomotic pressure) from 15 to $10 \mathrm{~mm} \mathrm{Hg}(P=.02)$ as the result of a lower mean subclavian artery pressure, although the mean arterial anastomotic pressure remained constant. Interruption of all the side branches resulted in a small and not significant increase in distal flow even after adenosine infusion. Conclusion: These observations suggest that blood flow in the side branches is minimal either at baseline and under combined systemic and coronary vasodilation. Clinically significant flow steal from the coronary circulation to the internal thoracic artery side branches seems then unlikely. (J Thorac Cardiovasc Surg 1999;118:66-70)
$\mathrm{R}$ ecent refinements of surgical technique and skills have made possible the construction of accurate left internal thoracic artery (LITA) to left anterior descending (LAD) anastomosis on the beating heart through a small anterior thoracotomy (the so-called MIDCABG procedure). In the absence of specific thoracic retractors or without thoracoscopic assistance, the ITA cannot be harvested in its full length and, as a consequence, the largest side branches (located in the first 2 intercostal

From the Departments of Cardiac Surgery ${ }^{\mathrm{a}}$ and Anesthesiology, ${ }^{\mathrm{b}}$ Catholic University, Rome, Italy.

Received for publication Oct 9, 1998; revisions requested Jan 12, 1999; revisions received Feb 24, 1999; accepted for publication March 2, 1999.

Address for reprints: Claudio Pragliola, MD, Divisione di Cardiochirurgia, Policlinico A Gemelli, Largo Gemelli 8, 00168 Rome, Italy.

Copyright (C) 1999 by Mosby, Inc.

$0022-5223 / 99 \$ 8.00+0 \quad \mathbf{1 2 / 1 / 9 8 4 2 8}$ spaces) are left patent in most patients undergoing the MIDCABG procedure.

However, some authors have speculated about the possibility that patent side branches might have a preferential flow and steal blood away from the coronary circulation, leading to angina recurrence or graft failure. ${ }^{1,2}$

This study, with the use of an animal model, was designed to evaluate the changes in the ITA flow associated with patent large side branches.

\section{Material and methods}

Surgical and anesthesiologic technique. All animals used in this study received humane care in compliance with the "Guide for the Care and Use of Laboratory Animals" published by the National Institutes of Health (NIH publication no. 85-23, revised 1985). After induction of anesthesia with ketamine $(20 \mathrm{mg} / \mathrm{kg})$ and pentobarbital sodium $(10 \mathrm{mg} / \mathrm{kg}$ given intravenously), 10 female Landrace pigs weighing 28 to $32 \mathrm{~kg}$ were intubated and their lungs ventilated with $100 \%$ oxygen. Pancuronium bromide was used at regular intervals to 
Volume 118, Number 1

Table I

\begin{tabular}{|c|c|c|c|c|c|c|c|c|c|}
\hline & $\begin{array}{l}\text { Heart rate } \\
\text { (beats/min) }\end{array}$ & $\begin{array}{c}M A P \\
(m m \mathrm{Hg})\end{array}$ & $\begin{array}{c}C I \\
\left(L / m / m^{2}\right)\end{array}$ & $\begin{array}{c}P F \\
(\mathrm{~mL} / \mathrm{min})\end{array}$ & $\begin{array}{c}D F \\
(\mathrm{~mL} / \mathrm{min})\end{array}$ & $\begin{array}{l}\text { Coll BF } \\
\text { (mL/min) }\end{array}$ & $\begin{array}{c}M S A P \\
(m m H g)\end{array}$ & $\begin{array}{c}M A A P \\
(m m H g)\end{array}$ & $\begin{array}{l}\text { Gradient } \\
\text { ( } \mathrm{mm} \mathrm{Hg} \text { ) }\end{array}$ \\
\hline \multicolumn{10}{|l|}{ Baseline } \\
\hline Open & $72 \pm 5$ & $78 \pm 6$ & $2.5 \pm 0.1$ & $32 \pm 3$ & $26 \pm 4$ & \multirow[t]{4}{*}{$6 \pm 3$} & $75 \pm 4$ & $60 \pm 3$ & $15 \pm 3$ \\
\hline Closed & $74 \pm 4$ & $75 \pm 5$ & $2.5 \pm 0.1$ & $29 \pm 2$ & $27 \pm 2$ & & $74 \pm 3$ & $62 \pm 3$ & $12 \pm 2$ \\
\hline Variance & $40 \pm 6$ & $37 \pm 6$ & $0.02 \pm 0.1$ & $14 \pm 3$ & $14 \pm 3$ & & $21 \pm 4$ & $18 \pm 4$ & $2 \pm 6$ \\
\hline$P$ & .88 & .43 & .47 & .09 & .12 & & .06 & .19 & .03 \\
\hline \multicolumn{10}{|l|}{ Adenosine } \\
\hline Open & $135 \pm 6$ & $70 \pm 3$ & $5.5 \pm 0.2$ & $118 \pm 14$ & $100 \pm 14$ & \multirow[t]{2}{*}{$18 \pm 3$} & $69 \pm 4$ & $58 \pm 3$ & $10 \pm 2$ \\
\hline Closed & $137 \pm 7$ & $71 \pm 4$ & $5.7 \pm 0.1$ & $107 \pm 15$ & $106 \pm 13$ & & $71 \pm 3$ & $60 \pm 4$ & $11 \pm 2$ \\
\hline Variance & $133 \pm 11$ & $47 \pm 6$ & $0.6 \pm 0.7$ & $42 \pm 6$ & $38 \pm 6$ & $8 \pm 2$ & $29 \pm 5$ & $26 \pm 5$ & $44 \pm 6$ \\
\hline$P$ & .85 & .92 & .13 & .42 & .54 & $1.4 \mathrm{E}-6$ & .65 & .55 & .92 \\
\hline
\end{tabular}

$\mathrm{P}$ values for differences between baseline and adenosine groups are reported in the text. $P F$, Proximal flow; $D F$, distal flow; $C o l l$ BF, collateral blood flow. Variance is indicated \pm SD of paired differences.

Table II

\begin{tabular}{|c|c|c|c|c|c|c|}
\hline $\begin{array}{l}\text { Collateral } \\
\text { status }\end{array}$ & $\begin{array}{l}\text { Proximal LITA } \\
\text { systolic flow } \\
\text { (mL/min) }\end{array}$ & $\begin{array}{l}\text { Proximal LITA } \\
\text { diastolic flow } \\
\text { (mL/min })\end{array}$ & $\begin{array}{c}\text { Proximal LITA } \\
\text { S/D flow }\end{array}$ & $\begin{array}{c}\text { Distal } \\
\text { systolic flow } \\
(\mathrm{mL} / \mathrm{min})\end{array}$ & $\begin{array}{c}\text { Distal } \\
\text { diastolic flow } \\
\text { (mL/min) }\end{array}$ & $\begin{array}{c}\text { Distal } \\
\text { S/D flow }\end{array}$ \\
\hline \multicolumn{7}{|l|}{ Baseline } \\
\hline Open & $16 \pm 2$ & $16 \pm 3$ & $1: 1$ & $10 \pm 3$ & $15 \pm 4$ & $1: 1.5$ \\
\hline Closed & $8 \pm 1$ & $20 \pm 2$ & $1: 2.5$ & $7 \pm 1$ & $17 \pm 1$ & $1: 2.8$ \\
\hline Variance & $2 \pm 1$ & $4 \pm 2$ & & $2 \pm 1$ & $6 \pm 2$ & \\
\hline$P$ & .00001 & .07 & & .006 & .5 & \\
\hline \multicolumn{7}{|l|}{ Adenosine } \\
\hline Open & $47 \pm 3$ & $71 \pm 4$ & $1: 1.5$ & $30 \pm 4$ & $70 \pm 3$ & $1: 2.3$ \\
\hline Closed & $31 \pm 2$ & $75 \pm 2$ & $1: 2.4$ & $33 \pm 3$ & $73 \pm 2$ & $1: 2.2$ \\
\hline Variance & $5 \pm 2$ & $27 \pm 4$ & & $12 \pm 3$ & $7 \pm 5$ & \\
\hline$P$ & .003 & .07 & & .7 & .09 & \\
\hline
\end{tabular}

$\mathrm{P}$ values for differences between baseline and adenosine groups are reported in the text. $S / D$, Systolic/diastolic. Variance is indicated \pm SD of paired differences.

maintain muscle relaxation. The femoral artery was exposed and cannulated to monitor systemic arterial pressure, and a median sternotomy was performed.

The right ITA (RITA) was then harvested as a skeletonized free graft. At this time, a large side branch was left unclipped but dissected for at least $1 \mathrm{~cm}$. The proximal and distal segments of the LITA were then dissected, with care taken not to interrupt any side branch. Heparin $(1 \mathrm{mg} / \mathrm{kg})$ was given, and the distal part of the LITA was transected, allowing it to bleed for a few seconds, and then anastomosed end to end to the previously obtained free RITA. In this manner, we created a new composite graft with the proximal part formed by the in situ LITA (with all its side branches patent) and the distal part by the free RITA (which could easily reach the LAD). This composite graft had all the proximal side branches patent and was long enough to reach the LAD (which would have been impossible with only the short distal segment of the LITA). The new conduit was arranged to place the large side branch of the original RITA in its distal portion. At this time a SwanGanz catheter (Baxter Healthcare Corp, Edwards Division, Santa Ana, Calif) was advanced into the pulmonary artery and propranolol (7.5-15 mg) was given to slow the heart rate.
The free edge of the new composite graft was anastomosed to the LAD without extracorporeal circulation with an 8-0 polypropylene suture. To monitor the pressure gradients across the new LITA, 2 Teflon catheters $(22 \mathrm{~F})$ were secured into the left subclavian artery and into the distal new LITA through the unclipped large side branch.

After the completion of the anastomosis, the LAD was ligated proximal to the origin of the first diagonal branch.

At the end of the study, all the animals were killed by an intravenous injection of pentobarbital sodium and potassium chloride. All the anastomoses were tested by passing a 1.5$\mathrm{mm}$ probe to confirm patency; only animals in whom perfect patency was documented were considered for data analysis.

Flow measurements. After 30 minutes of stabilization 24 mm flow probes (Flowmeter CM 1000 Medi-Stim AS; CardioMed, Oslo, Norway) were positioned, respectively, at the origin of the LITA from the subclavian artery to monitor the proximal flow and close to the LAD anastomosis to monitor the anastomotic or distal flow. For the purpose of this study, we assumed the difference between these 2 measured values to be the flow in the side branches (Fig 1).

The following variables were recorded: heart rate, mean 


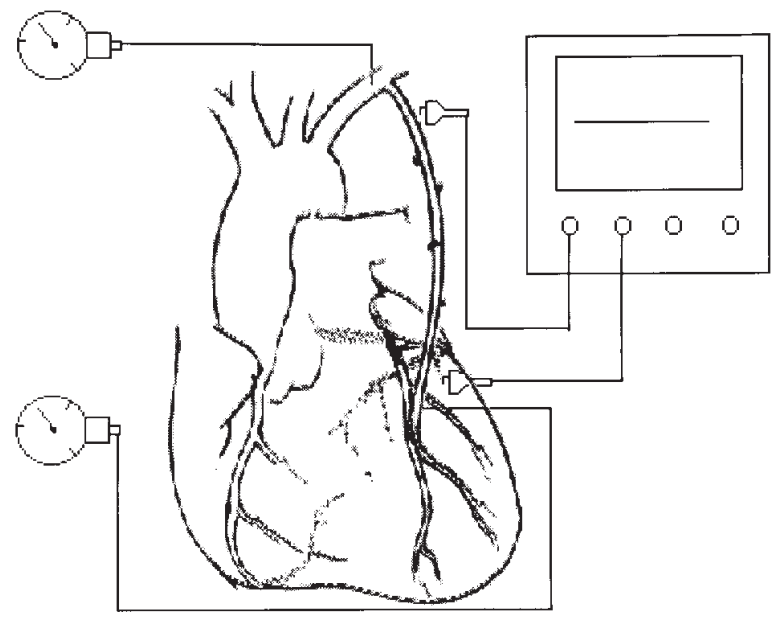

Fig 1. Experimental design.

arterial pressure (MAP), cardiac index (CI), proximal flow, distal flow, flow in the side branches, mean subclavian arterial pressure (MSAP), and mean anastomotic arterial pressure (MAAP).

Adenosine $0.5 \mathrm{mg} / \mathrm{kg} / \mathrm{min}$ was then infused in the central venous line; after 5 minutes of stabilization, the measures were repeated. During the adenosine infusion, the MAP was maintained at 70 to $80 \mathrm{~mm} \mathrm{Hg}$ with the use of plasma expanders.

For the second part of the protocol, the side branches of the LITA were identified and clipped, and the study was repeated.

For the statistical studies, a strip of 10 consecutive beats was recorded after stabilization and analyzed. Each cardiac cycle of a sequence was plotted, analyzed, and averaged with the others with the SigmaScan software (Jandel Scientific Gmbh Erkrath FR, Germany) to determine the systolic and diastolic flows.

The Student $t$ test for paired data was used to assess differences in the same animal under the different conditions. The SPSS/PC statistical software (SPSS, Inc, Chicago, Ill) was used to compute the data. Results are presented \pm SD.

\section{Results}

Detailed results of the hemodynamic measurements during the conditions tested are given in Table I.

With all the proximal side branches open, the blood flow in the side branches was $6 \pm 3 \mathrm{~mL} / \mathrm{min}$, representing $18 \%$ of the total flow.

After the infusion of adenosine, we observed a $9 \%$ decrease of the MAP, a $220 \%$ increase of the CI, a $368 \%$ increase of the proximal flow, a 384\% augmentation of the distal flow ( $P=7 \mathrm{E}-6$, with respect to baseline values), and a threefold increase of the side branch flow (p6E-5; Table I). However, the fractional value of side branch flow was $15 \%$ of the proximal flow in the proximal LITA.
With the side branches clipped, proximal and distal flow became equivalent, but the increase in distal flow (caused by the abolishment of side branch flow) was not significant (Table II).

The pressure gradient across the new LITA was 15 $\mathrm{mm} \mathrm{Hg}$ at baseline conditions. The occlusion of the side branches reduced this gradient to $12 \mathrm{~mm} \mathrm{Hg}(P=$ .03). Interestingly, the infusion of adenosine caused a further reduction of the gradient to $10 \mathrm{~mm} \mathrm{Hg}$ with the side branch flow open (variance, $4 \pm 5 ; P=.02$, compared with the respective baseline gradient) and to 11 $\mathrm{mm} \mathrm{Hg}$ with the side branch flow closed (variance, $4 \pm$ $4 ; P=.08$, compared with the respective baseline gradient). This reduction of the gradient was caused by a reduction of the MSAP, while the driving MAAP remained stable in all the 4 conditions tested (Table I) because of the autoregulation of the coronary vascular bed.

The analysis of the flow curves showed some striking differences between the different experimental conditions (Table II). The flow curves in the proximal LITA were similar to those usually observed in large elastic vessels (like the subclavian artery), so that, in this position at baseline conditions, the systolic flow was equivalent to the diastolic flow (systolic/diastolic flow ratio, $1: 1 ; P=.09)$. This morphologic feature of the curve was different from that recorded in the distal portion of the conduit, where the diastolic flow was clearly higher than the systolic (systolic/diastolic flow ratio, 1:1.5; $P=.002$; Fig 2).

After the infusion of adenosine elastic, characteristics of the proximal LITA were enhanced, resulting in an increase of the diastolic flow both proximally and distally and in an inversion of the flow in late systole that was attenuated along the course of the vessel and disappeared at the level of the anastomosis (Fig 3).

During the infusion of adenosine and with the side branches open, the systolic/diastolic flow ratios in the proximal and distal LITA were $1: 1.5(P<.006)$ and 1:2.3 $(P=.005)$, respectively. Despite the fact that these values differed from those observed at baseline, the absolute value of the diastolic flow remained constant (proximal diastolic flow, $71 \pm 4 \mathrm{~mL} / \mathrm{min}$; distal diastolic flow, $70 \pm 3 \mathrm{~mL} / \mathrm{min}$ ) and equivalent to those observed when the side branches were clipped (Table II).

\section{Discussion}

The visualization of large LITA side branches during angiographic follow-up in patients with recurrent postoperative angina does not necessarily imply that a steal syndrome occurs.

In fact, the possibility of blood flow diversion from 


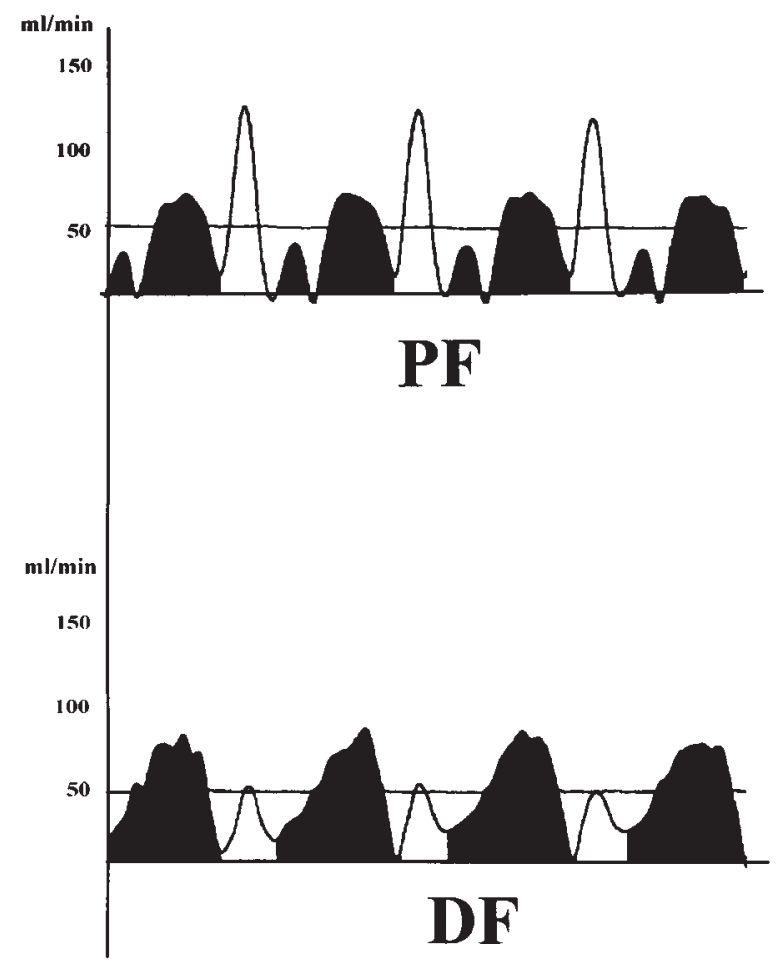

Fig 2. Baseline proximal $(P F)$ and distal $(D F)$ flow curves recorded with the collateral branches open. Systole (blank) and disastole (solid) are shown.

LITA to open side branches is still debated. This phenomenon has been either emphasized ${ }^{3,5}$ or rejected in studies that used an intracoronary infusion of adenosine and angiographic ${ }^{6,7}$ and intravascular Doppler ${ }^{8,9}$ techniques.

However, the isolated coronary vasodilation caused by the infusion of adenosine is likely to reduce the possibility of flow steal without a simultaneous reduction of systemic vascular resistance.

In our study, adenosine was administered by central venous infusion that led to simultaneous systemic and coronary relaxation (as demonstrated by the doubled CI and the quadrupled LITA flow).

Using this model, we found that the flow to LITA collaterals represented almost $18 \%$ of the total LITA flow at baseline and that this proportion was even further reduced after adenosine infusion (despite the fact that LITA flow increased by $368 \%$ ).

Moreover, either at rest or with systemic and coronary relaxation, the flow at the anastomotic level increased only slightly, and the distal flow remained constant after closure of the side branches, thus testifying to the small hemodynamic importance of the LITA collaterals (Table II).

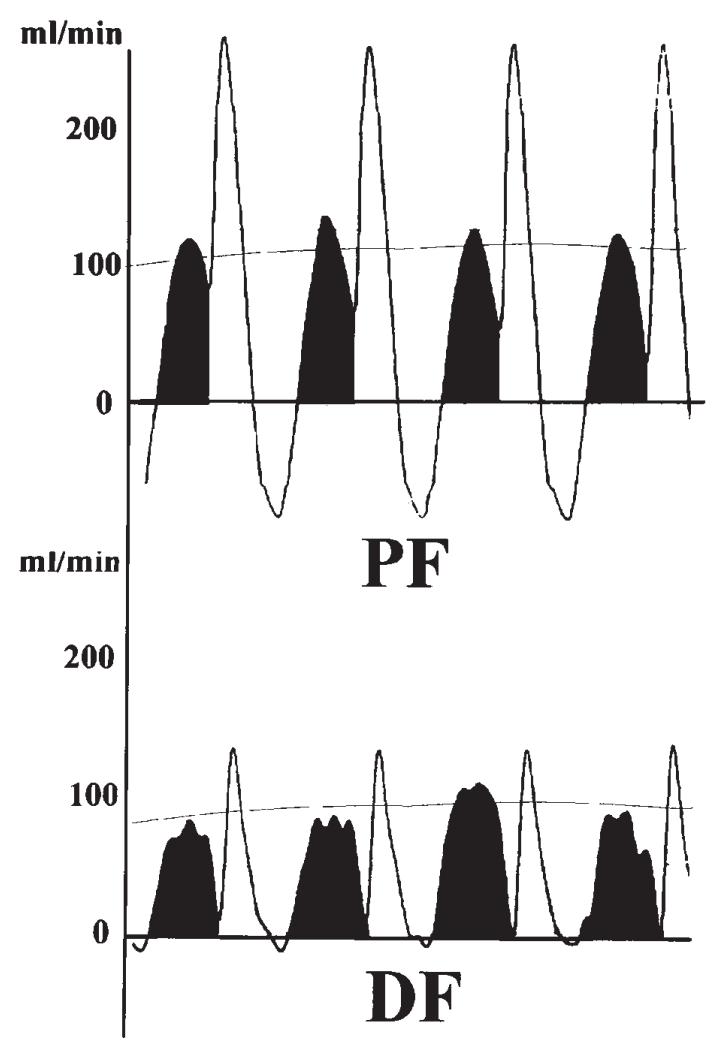

Fig 3. Proximal $(P F)$ and distal $(D F)$ flow curves recorded after adenosine infusion with the collateral branches open. Systole (blank) and disastole (solid) are shown.

In fact, after collateral closure, the decrease of the proximal flow was always limited to a few milliliters even after the infusion of adenosine.

In agreement with these data, we recently confirmed the minimal potential flow steal of the LITA branches using an Doppler echocardiographic method in human beings. ${ }^{10}$

It is also noteworthy that the LITA can accommodate wide variations of flow with minimal pressure drops along its course.

In the normal coronary circulation, ${ }^{11,12}$ the pressure drop from the aorta to the large epicardial vessels is about 10\%; in our study this reduction of pressure ranged from $17 \%$ to $20 \%$, with the lowest values of the gradient recorded with the infusion of adenosine. These higher values can be explained by the unusual length of the conduit in our model. More important, the gradient between the MSAP and MAAP is maintained, and it is even decreased with increased fourfold flow.

This response kept the driving coronary pressure in the normal range as a result of combined LITA and coronary 
autoregulation. In this model, the burden imposed on the LITA by the side branches to the chest wall remained generally stable despite the fact that the absolute value of this collateral circulation increased 3 times.

On the basis of these data and the results of our investigations performed in human beings, ${ }^{10,11}$ it is our impression that diversion of blood flow from the coronary system to the side branches is extremely rare unless technical imperfections or anatomic factors (like a small caliber of the distal LITA or the target vessel) reduce the LITA runoff. This was also confirmed in our group of patients who were re-evaluated after MIDCABG with a LITA graft to the LAD with a transthoracic Doppler method. ${ }^{13}$

Resolution of postoperative angina has been achieved with percutaneous transluminal coronary angioplasty of stenotic LITAs without complete embolization of the large collateral branches detected during the procedure. ${ }^{14,15}$

It is reasonable to assume that, in these cases, the resolution of the stenosis ameliorated the ITA runoff, restored the normal ratio between the ITA graft and collateral branch resistances, and minimized the diversion of flow into the collaterals.

According to these considerations, it would have been interesting in our model to evaluate the presence of steal phenomenon with increasing degrees of distal stenosis of the new LITA. In planning this study, we deliberately decided not to proceed with this test because it was extremely difficult to determine the exact percentage of stenosis that we could generate. We also considered that simulating a stenotic anastomosis would be misleading because a perfectly patent anastomosis in coronary surgery is the gold standard and the only acceptable result.

In conclusion, our data demonstrate that the hemodynamic significance of patent LITA graft collaterals is limited, even in the condition of combined systemic and coronary dilatation; these observations seem to deny the possibility of significant flow steal by these branches from the larger coronary circulation even in patients undergoing the so-called $\mathrm{H}$ graft-MIDCABG, in which a radial or right inferior epigastric artery is anastomosed to an in situ LITA to reach the LAD artery. ${ }^{16}$

\section{REFERENCES}

1. Schmid C, Heublein B, Reichelt S, Borst HG. Steal phenomenon caused by a parallel branch of the internal mammary artery. Ann Thorac Surg 1990;50:463-4.

2. Singh RN, Sosa JA. Internal mammary artery-coronary anastomosis: influence of the side branches on surgical result. J Thorac Cardiovasc Surg 1981;82:909-14.

3. Nakhjavan FK, Koolpe HA, Bruss J, Najhi M, Radke T. Transcatheter coil occlusion for treatment of left internal mammary: anterior descending artery steal phenomenon. Cathet Cardiovasc Diagn 1993;28:347-50.

4. Ayres RW, Lu CT, Benzuly KH, Hill GA, Rossen JD. Transcatheter embolization of an internal mammary artery bypass graft side branch causing coronary steal syndrome. Cathet Cardiovasc Diagn 1994;31:301-3.

5. Mishkel GJ, Willinsky R. Combined PTCA and microcoil embolization of a left internal mammary artery graft. Cathet Cardiovasc Diagn 1992;27:141-6.

6. Ivert T, Huttunen K, Landou C, Björk VO. Angiographic studies of the internal mammary artery 11 years after coronary artery bypass grafting. J Thorac Cardiovasc Surg 1988;96:1-12.

7. Kuttler H, Hauenstein KH, Wenz W, Schlosser V. Significance of early angiographic follow-up after internal thoracic artery anastomosis in coronary surgery. Thorac Cardiovasc Surg 1988;36:96-9.

8. Kern MJ, Bach RG, Donohue TJ, Caracciolo EA, Wolford T, Aguirre FV. Role of large pectoralis branch artery in flow through a patent left internal mammary artery conduit. Cathet Cardiovasc Diagn 1995;34:240-4.

9. Luise R, Teodori G, Di Gianmarco G, et al. Persistence of mammary artery branches and blood supply to the left anterior descending. Ann Thorac Surg 1997;63:1759-64.

10. Gaudino M, Serricchio M, Glieca F, et al. Steal phenomenon from mammary side branches: When does it occur? Ann Thorac Surg 1998;66:2056-62.

11. Maseri A. The coronary circulation. In: Maseri A, editor. Ischemic heart disease. 1st ed. New York: Churchill Livingstone; 1997. p. 71-103.

12. Klassen GA, Armour JA, Garner JB. Coronary circulatory pressure gradients. Can J Physiol Pharmacol 1987;65:520-5.

13. Gaudino M, Serricchio M, Tondi P, et al. Do internal mammary artery side branches have the potential for hemodynamically significant flow steal? Eur J Cardiothoracic Surg. In press.

14. Ishizaka N, Ikari Y, Saeki F, et al. Repeat embolization of the side branch of the internal mammary artery graft by gelatin sponge particles and micro coils. Cathet Cardiovasc Diagn 1995;34:245-9.

15. Mishkel GJ, Willinsky R. Combined PTCA and microcoil embolization of a left inernal mammary artery graft. Cathet Cardiovasc Diagn 1992;27:141-6.

16. Cohn WE, Suen HC, Weintraub RM, Johnson RG. The H graft: an alternative approach for performing minimally invasive direct coronary artery by pass. J Thorac Cardiovasc 1998;115:148-51. 